\title{
El catecumenado en «De catechizandis rudibus»
}

La presente contribución al hecho de conmemorar el acontecimiento de la conversión de S. Agustín, se convierte en la oportunidad de reflexionar sobre uno de sus tratados más conocidos, y que ha tenido gran resonancia en numerosas ocasiones en la catequética. Ciertamente el hecho de que Agustín escribiera el tratado De catechizandis rudibus al filo del año 400, con aproximadamente 46 años de edad, tras 13 años de converso, hace que tal escrito recoja una parte notable de sus experiencias en orden al tratamiento adecuado que ha de proporcionarse a los nuevos conversos con los que el diácono Deogracias, destinatario primero del escrito, tiene que tratar habitualmente.

Sabemos perfectamente de la práctica común de la Iglesia del siglo IV respecto al catecumenado de adultos, como forma más extendida de aproximación al cristianismo y de acceso al bautismo. De ahí las nuevas resonancias que esta obra produce en momentos de la vida actual de la Iglesia en que la implantación de un catecumenado de adultos de nuevo cuño comienza a ser una tendencia común, fruto de las nuevas necesidades. Echar la vista atrás para conocer el funcionamiento, los aciertos y dificultades del catecumenado del que Agustín participó como catecúmeno y como pastor de la Iglesia, ayuda a situar en una relativización fecunda los actuales esfuerzos.

Por ello, vamos a detenernos menos en el enfoque metodológico, desde el que ha sido más frecuentemente contemplado el De catechizandis rudibus y vamos a procurar resaltar los acentos catecumenales contenidos en dicha obra.

\section{CONCEPTO DE CATECÚMENO}

El catecumenado estaba estructurado en tres etapas, dos previas al bautismo, y una posterior a él. La primera es la de preparación remota, a la que tienen acceso los catechoumenoi (en Oriente) o los audientes (en Occidente); a 
ésta sigue la de preparación próxima para el bautismo, seguida por los que Oriente denomina como photizomenoi, y Occidente como electi. Y tras el bautismo tienen lugar las catequesis mistagógicas, más breves, que completan la instrucción del sacramento que acaban de recibir los neófitos. A la primera de las etapas mencionadas precedía otro período de aproximación al cristianismo ${ }^{1}$, de somera información (especialmente en las épocas en que ésta no era de dominio público), de sintonía inicial y que en la terminología actual se calificaría como de estado de misión, designando a los que se aproximaban pero aún no se habían decidido a ingresar en el catecumenado con la expresión accedentes, de empleo occidental, y en el caso concreto de S. Agustín, con la equivalente de rudes ${ }^{2}$.

El hecho de la institucionalización del catecumenado con anterioridad a S. Agustín, había contribuido a dotar al catecúmeno de una cierta estabilidad, no definitiva, sin embargo. La estabilidad estaba justificada por el hecho de respetar los pasos o etapas establecidos en el proceso de iniciación cristiana, de manera que no se improvisara precipitadamente el acceso a la fe, máxime a la vista de la situación de los «lapsi» que durante la persecución de Decio inquietaron a la comunidad cristiana, especialmente la norteafricana, acerca de las verdaderas exigencias que proporcionaran a un nivel humano la garantía de la fe. Por otro lado, provisionalidad, pues no se trata de un estadio definitivo, sino de iniciación y acceso a la plena condición de bautizado. De ahí que una de las causas de la decadencia del catecumenado fue la tendencia, mitad pereza, mitad comodidad, de prolongar indefinidamente la situación de catecúmeno, estabilizándose en este estadio menos comprometido que el del fiel bautizado.

De ahí que nada tenga de particular la consideración que incluso en el seno de la Iglesia tenga la condición de catecúmeno, distinta ciertamente de la del fiel bautizado, pero aceptado ya como miembro de la comunidad:

«Pregunta a un hombre: ¿Eres cristiano? Te responde que no. ¿Eres pagano

1. Las etapas del catecumenado están descritas en J. Danielou,-R. Du Charlat, La catequesis en los primeros siglos, Madrid, Studium 1975, 37-42. Ver también: D. Borobio, Catecumenado, en C. Floristan,-J.J. TAmayo, (Ed.), Conceptos fundamentales de Pastoral, Madrid, Cristiandad 1983, 99-120; G. Groppo, Catecumenato antico, en J. GeVAERT, (ed.), Dizionario di Catechetica, Leumann-Torino, LDC 1986, 133-136; I. RoDRíGUEZ, El catecumenado en la disciplina de África según san Agustín. Contribución española a una Misionología Agustiniana, Burgos 1955; y en general toda la abundante bibliografía actual sobre el catecumenado, vgr. G. GROPPo, Catecumenado antiguo, en J. Gevaert (ed.) Diccionario de catética, Madrid, CCS 1987, 146149.

2. «Rudo» no es el inculto, sino el que ignora el contenido de la fe: F. CAMPo, La Catequesis Pastoral en el «De Catechizandis rudibus», en «Estudio Agustiniano» 7 (1972) 111; son aquellos a los que hay que dar los rudimentos de la fe; aquellos cuya iniciación está enteramente por comenzarse (J. DANIELOU..., o.c., 218), «los que empiezan» (A. ETCHEGARAY, De catechizandis rudibus, en «Helmantica» 22 [1977] 27). 
o judío? Si te contesta que no, le vuelves a preguntar: ¿Eres catecúmeno o fiel? Si te dice que es catecúmeno, está untado, aún no está lavado» ${ }^{3}$.

De ahí que sea aceptado, sin rechazo, aunque ciertamente en un estadio aún imperfecto de la fe, pues no sólo no ha llegado todavía a la plena recepción de los sacramentos, ni a la consiguiente integración en la Iglesia, sino que aún le resta mucho por aprender respecto a las afirmaciones últimas y al sentido pleno que tiene el dogma cristiano:

«Los catecúmenos son así; ellos ya creen en el nombre de Jesucristo; pero Jesús no se les confía (...). Se dice al catecúmeno: ¿Crees en Cristo? Y él contesta: Sí, creo, y se hace la señal de la cruz; lleva ya en la frente la cruz de Cristo y no se ruboriza de la cruz de su Señor. Ésta es la señal de que creyó en su nombre. Hagámosle otra pregunta: ¿Comes la carne y bebes la sangre del Hijo del hombre? No entiende lo que le decimos: es que Jesús aún no se ha confiado o entregado a él» ${ }^{4}$.

Tal distinción establece no tanto una diferencia jerárquica u organizativa en la Iglesia, sino principalmente una diferencia cualitativa, ya que el catecúmeno se encuentra todavía incapacitado para una plena inteligencia de cuanto constituye el pensamiento y la praxis de la Iglesia. Con mayor razón aún, los simpatizantes todavía no iniciados, los «rudes»: hablando a propósito de la eucaristía, como ocurría en el texto anteriormente citado, dice S. Agustín:

«Quienes oisteis esto, no todos conseguisteis entenderlo. Los que estáis bautizados y sois fieles, sabéis perfectamente lo que dice. Los que entre vosotros os llamáis catecúmenos o audientes, podéis ser oyentes a medida que se lee, pero ¿acaso podéis entenderlo» ${ }^{5}$.

Ahora bien, con enorme cordura, tal diferencia cualitativa es para Agustín únicamente la que marca el haber accedido a la plena posición de la fe, $o$ estar en trance de conseguirlo en lo que se refiere a la fe sabida o poseída, pero no en lo que mira a la fe vivida, a la puesta en práctica y, en definitiva, a la calidad o condición moral de la que Dios va a ser único juez, y que le lleva a preferir en ocasiones al catecúmeno que al mal cristiano o al hereje:

«En esta cuestión, no dudo ni por un momento en anteponer un catecúmeno católico imbuido de la caridad divina a un hereje bautizado; e incluso en el seno mismo de la Iglesia, anteponemos un buen catecúmeno a un mal bautizado...» ${ }^{6}$.

Con lo que antecede hemos podido apreciar tanto los mecanismos previstos para formar parte de la comunidad cristiana, como la acogida dispensada

3. In Joa. ev., 44,2.

4. In Joa. ev., 11,3.

5. Sermón 132, 1,1 .

6. De bapt., IV, 21,28 . 
a quienes están próximos a serlo; y no obstante el grado de pertenencia sociológica, prevalece el grado de pertenencia cordial y vital, mensurable únicamente por Dios, pero perceptible por la Iglesia y por la aguda visión de Agustín.

Cuando Agustín escribe cualquiera de los párrafos que anteceden, lo hace desde su perspectiva de pastor y de obispo, preocupado de la edificación de su iglesia, para la que desea las mejores condiciones posibles para el crecimiento de la fe. Pero es imposible olvidar que habla desde su propia y personal experiencia, ya que también él ha pasado por el catecumenado que le ha dado acceso a la plenitud de la fe. Su conversión no es únicamente la decisión firmemente tomada de emprender el camino cristiano: es también el fruto de una larga inquietud no saciada en otras fuentes y que le llevó a dar el paso de abrazar la fe de la Iglesia católica, llegando a ella a través del catecumenado.

«Agustín buscó la verdad con inquietud. La buscó en la soledad de sus reflexiones, en la conversación con sus amigos cristianos, en la lectura de la Sagrada Escritura, en la escuela de la predicación del obispo de Milán, san Ambrosio, y en una progresiva aproximación a la Iglesia de Cristo, la comunidad en la que únicamente se puede profesar la fe autentica en el Dios vivo. Agustín recuerda con emoción en sus escritos las oraciones de su madre santa Mónica, que pidió a Dios con perseverancia la conversión de su hijo, y reconoce que ella, una sencilla mujer sin letras - pero cristiana- había alcanzado la cumbre más alta de la sabiduría. Agustín, convertido en el otoño del 386, recibió el bautismo en la Pascua del año siguiente, el 25 de abril, después de seguir el proceso catecumenal. Quien, más adelante va a ser modelo de catequistas, comienza siendo ejemplo de catecúmenos» ${ }^{\text {? }}$.

Él tuvo también la oportunidad de aproximarse a las verdades de la fe cristiana, de llegar a depurar su estilo de vida de los resabios del pasado, de gustar la novedad del planteamiento que reclamaba su íntimo descubrimiento de Cristo, de dejarse guíar de la mano de quienes le fueron clarificando los misterios de la fe, y de acompañar y dejarse acompañar por quienes accedie-

7. J.M. EsTEPA, Conmemoración de veinte años de renovación catequética en España a la Luz del Concilio Vaticano II, en «Actualidad Catequética» 26 (1986) 358.

Llama la atención la brevedad del período de catecumenado seguido por san Agustín, sobre todo a la luz de la recomendación de HiPólito, (Traditio Apostolica, 17): «Los catecúmenos serán instruidos oralmente durante tres años». Pero a continuación, se advierte que «Si alguno fuera celoso y aplicado en el cumplimiento de sus obligaciones, no se juzgará el tiempo, sino solamente la conducta» (Edición de Salamanca, Sígueme 1985, 73). Hay que tener presente que tan largo tiempo estaba justificado en el siglo III por las numerosas defecciones habidas en las persecuciones, lo que obligaba a elevar las exigencias para el bautismo (J. DANIELOU-R. DU CHARLAT, o.c., 43). Y ya no son las circunstancias en que se mueve Agustín, tras la publicación del Edicto de Milán (313). De manera que el propio Agustín recomienda para las personas cultas en De catechizandis rudibus $(8,12)$ que «con éstos se ha de obrar con brevedad, y no inculcando odiosamente lo que ya conocen» lo que supone un catecumenado más breve que el que resultaba habitual hasta poco tiempo antes. 
ron conjuntamente con él a las aguas bautismales. Puede, pues, aconsejar a los catecúmenos pues ha descubierto el valor del recorrido de las etapas catecumenales, del progresar en la sabiduría cristiana, hasta llegar a hacer suya la fe de la Iglesia.

\section{LA CONVERSIÓN}

Importa centrarse en este punto de la reflexión que Agustín ofrece al diácono Deogracias, para ilustrarle acerca de lo que debe perseguir prioritariamente de cara a la relación que tiene con los catecúmenos que aspiran a la militancia en el seno de la Iglesia. Hacerlo en el centenario de la «conversión» del propio Agustín sirve como motivo adicional para traer a la memoria que él no habla desde la teoría de lo que se debería hacer, sino de los pasos posibles que hay que realizar y llevar a cabo en orden al cambio interior y profundo de la persona, vuelta hacia Cristo. $Y$ sabiendo por personal experiencia lo que supone ese paso («iQué tarde te conocí!»), se siente en condiciones de aconsejar a otro sobre las cautelas a evitar, los acentos que pone y el punto central de la conversión.

De ahí que apunte al centro mismo del problema de la conversión cuando la plantea en términos de interiorización, de lo más profundo y singular de la persona, y no queda reducida a la pura apariencia o a los gestos vacíos de sentido:

«La fe no es el hecho de un cuerpo que se postra, sino de un alma que cree» ${ }^{8}$.

Como es lógico, no hay que tratar de ver en la expresión citada la dicotomía cuerpo-alma, como si la esencia irreductible de la persona estuviera constituida por lo anímico y espiritual, mientras que lo corporal resultara un mero accidente. Ahora bien, la vaciedad de lo superfluo podría llevar a la mera valoración de los gestos externos que ciertamente no sostienen si no es en conexión con los sentimientos profundos: la verdadera conversión es la conversión del corazón. Y los gestos, los signos, «el cuerpo que se postra» terminan por ser la exteriorización «del alma que cree». Unidos ambos aspectos, adquieren toda su verdadera dimensión; disociados, terminan por ser ficticios. Y Agustín señala a Deogracias de qué debe huir para acertar con la verdadera conversión. Ahora bien, el catequista no se encuentra en condiciones de juzgar con evidencia absoluta cuándo se produce tal conversión, sino que debe posibilitar que ésta tenga lugar, desempeñando un lugar importante, secundario - pero necesario- en el proceso y en la decisión última del converso:

«Desconocemos cuándo se rinde interiormente aquel a quien vemos ya exte-

8. De catechizandis rudibus, 5,9 . 
riormente presente; pero sin embargo debemos portarnos con él de forma que, aunque no haya voluntad de aceptación, se produzca»" ${ }^{9}$.

Es el juego de la acción eficaz de la gracia de Dios, que quiere contar con la limitada pero eficiente colaboración humana, que pese a todo, sigue siendo secundaria. De ahí el desconocimiento de la profunda y fundamental rendición interior, que es en último término la que cuenta: es éste un definitivo gesto de aceptación perceptible únicamente para Dios en el momento de producirse, y de que los hombres podemos percibir, juzgar y evaluar su existencia por el signo evangélico de los frutos que testimonian el cambio que se ha producido en lo íntimo del corazón (Mt 7, 16-17). Pero además de apreciar la existencia de la conversión, el catequista está llamado a crear las condiciones en las que ésta sea posible, facilitando la rendición interior.

En esa línea se sitúa la recomendación de conectar con los intereses personales de los catecúmenos ${ }^{10}$, de manera que

«no será inútil el preguntarle por qué motivo se vio impelido a querer ser cristiano» ${ }^{11}$.

pues ello va a proporcionar las pistas que hagan posible el paso de la conversión. El conocimiento de la trayectoria humana hace que la actuación del catequista no resulte anónima y despersonalizada, sino adaptada y singular para las condiciones y los motivos concretos que han impulsado a cada persona a una inicial aproximación a la fe. Sólo así será «eficaz» con la eficacia de los medios humanos al servicio de la conversión.

Agustín recomienda también la prudencia pedagógica de escuchar y tener en cuenta los motivos iniciales, que no siempre han de ser los más válidos si se consideran desde la óptica ideal de la fe, pero que son subjetivamente importantes hasta que son puestos en contraste con los verdaderos motivos, frente a los cuales, otros se desvanecen o pasan a un lugar absolutamente secundarios:

«Y si acaso dijese [el catecúmeno] que él por inspiración divina estaba advertido o amedrentado para hacerse cristiano, nos ofrece, en cuán grande es el cuidado de Dios por nosotros, un acceso sumamente consolador para el comienzo de la instrucción. Razonablemente su solicitud ha de ser conducida, de milagros y ensueños de esta clase, al camino más sólido y a los oráculos más ciertos de la Escritura..." ${ }^{12}$.

de forma que sin despreciar los motivos iniciales, éstos puedan ser purifica-

9. Id., 5,9.

10. San Agustín habla concretamente en esta ocasión de los motivos que pueden tener los catecúmenos dotados de cultura profana. Como es obvio, tal indicación tiene únicamente el valor de un ejemplo de lo que procede realizar en cada caso según la situación y posibilidades peculiares de cada catequizando.

11. De catechizandis rudibus, 8,12 .

12. Id., 6,10 . 
dos, confrontados con otros y, en definitiva, suave y prudentemente substituidos por los más centrales en la dinámica de la fe, como son «los oráculos más ciertos de la Escritura».

Esto nos lleva de la mano a la enumeración de una serie de motivos que, con vistas a la verdadera conversión han de ser acogidos pero depurados puesto que no resultan válidos ni dignos de ser tenidos en cuenta como únicos para la aceptación de una persona en el catecumenado y posteriormente en la comunidad. En primer lugar, y en atención al cambio de situación producido en el disfrute de la paz constantiniana y la afluencia masiva de conversiones, Agustín previene contra el atractivo de que pueda estar de moda hacerse cristiano como hace la mayoría, así como conformarse con una medianía poco exigente en cuanto a la calidad y más preocupada de guardar las apariencias:

«Advirtamos a quien es adoctrinado que se aleje de imitar a los que son cristianos, no de verdad, sino de sólo nombre; que se abstenga de seguirlos, arrastrado por su número...»" ${ }^{13}$.

Arropados, sin duda, por el número creciente de cristianos, se ha producido una degradación de la vida cristiana, que parece tentar a muchos paganos a abrazar una nueva fe poco consecuente en la vida práctica y que dista mucho de ser la ideal, pero que es la que en gran manera están viendo reflejada en un cristianismo decadente. Apetecer la vida cristiana devaluada ya en la intención de los catecúmenos es otra preocupación de Agustín:

«Pero especialmente se habrá uno de guardar de ser tentado y de ser embaucado por los que están dentro de la Iglesia católica; éstos son los que se mantienen en su seno al modo de la paja hasta el día de ser aventada (...). Te encontrarás a muchos hombres dados a la bebida, avarientos, defraudadores, enviciados en el juego, adúlteros, lujuriosos, personas que se entregan a soluciones sacrílegas, que se fían completamente de encantadores, astrólogos y visionarios de cualquier otro género blasfemo. También te podrás percatar de que aquellas masas de personas que llenan los templos los días festivos del Cristianismo son los mismos que ocupan al completo los teatros en los días de fiestas paganas. $Y$ este espectáculo te arrastrará a imitarlos» ${ }^{14}$.

Hablando sin rodeos a la hora de señalar las lacras de un cristianismo poco exigente consigo mismo, Agustín lamenta una situación tal que ejerce en el ánimo del pagano una fuerte seducción por cuanto se adhiere a la nueva religión oficialmente constituida, pero haciéndola compatible con una vida prác-

13. De catechizandis rudibus, 14,21. El fin de la persecución se constata de la siguiente forma: «Ante la muerte en número incontable de estos [mártires] por todas las naciones en testimonio de la verdad de la fe, inclusive los mismos poderes que les perseguían cayeron y se convirtieron, abatida su cabeza orgullosa, al conocimiento y la veneración de Cristo» (Id., 24,44; expresiones paralelas también en Id., 27, 53).

14. Id., 25,48 . 
ticamente pagana, lo que inutiliza la verdadera conversión en cuanto cambio de corazón expresado en cambio de conducta.

Otro falso motivo que ha de ser eliminado es la existencia de intereses inconfesables al solicitar el ingreso en la Iglesia, intereses que, sin duda, tienen que ser rechazados por lo que implican de búsqueda de motivos humanos, aunque estén revestidos de una cierta religiosidad:

«Hay quienes quieren ser cristianos para ganarse la confianza de los hombres de los que esperan unas ventajas temporales, o porque no quieren ofender a quienes temen. Pero ésos han de ser objeto de reproche (...). Otros, con una mejor esperanza, pero con no menos peligro, temen, desde luego, a Dios, no se burlan del nombre de cristianos, entran en la Iglesia de Dios con un corazón sincero, pero esperan la felicidad en esta vida: han de ser más felices en las cosas terrenas que los que no aceptan a Dios» ${ }^{15}$.

Resulta obvio comprobar que tales motivos sean absolutamente incompatibles con el hecho de ser cristianos, y hayan de ser rechazados de plano, pues difícilmente pueden ser modificados o alterados. Con planteamientos semejantes, resulta imposible la conversión sincera. Por ello, inmediatamente antes ha manifestado que, como modelo de una posible catequesis, se le diga al catecúmeno:

«Tú no viniste a unirte a la Iglesia de Dios para buscar en ella alguna utilidad temporal» ${ }^{16}$.

$\mathrm{Y}$ en ese mismo lugar se explaya en una serie de aspectos y conductas que resultan incompatibles con el ser cristiano como es la vida licenciosa, la pasión por el espectáculo de los gladiadores en el circo, las francachelas, las batallas de los teatros, la podredumbre de las fornicaciones, etc..., de manera que la verdadera conversión pasa por el planteamiento de abandono de la vida anterior, como el propio Agustín hubo de hacer con ocasión de la lectura de la carta a los Romanos. De manera que como conclusión de todos estos falsos motivos que pueden impulsar a una aparente conversión, afirma con enorme cordura que es preciso establecer la diferencia entre la pertenencia sociológica, visible, y la pertenencia cordial, invisible, pero eficaz al grupo de los salvados:

«Y sobre los perversos, aunque estén dentro del recinto de un templo, no pienses que por ello habrán de estar dentro del recinto del reino de los cielos» ${ }^{17}$.

15. De catechizandis rudibus, 17,26. Algo semejante dice en $I d ., 5,9:$ «...pues si quiere hacerse cristiano para esperar alguna ventaja de parte de los hombres, a los que, piensa, no puede agradar de otra manera, o para evitar algún perjuicio de quienes teme la enemistad o la injuria, no es que quiera serlo [cristiano] realmente, sino simularlo».

16. Id., 16,25 .

17. Id., 27,55. Un pensamiento similar fue manifestado por Agustín en otros lugares: «Son numerosos los hombres que Dios reconoce como suyos, pero no la Iglesia; son también numerosos los hombres que la Iglesia los reconoce, pero no Dios». 
En consecuencia, advierte al catequista que en determinadas ocasiones los motivos de un catecúmeno en su acceso a la religión han de ser suficientemente atendidos y canalizados de manera que puedan ser modificados en verdaderos y suficientes como para sustentar una sincera conversión:

«Mas si él dice, en efecto, con una intención digna de elogio, bien diga la verdad, bien mienta, mediante la aprobación y la alabanza de la determinación con que él dice haber venido, hagamos que se deleite en ser tal cual desea ser considerado. Pero si hace alguna afirmación que choca con los sentimientos que debe tener en el alma un candidato, que ha de ser iniciado en la fe cristiana, habrá de ser reprendido con toda delicadeza, como inculto y falto de conocimientos y demostrar con brevedad y seriedad, en su total verdad, el fin de la doctrina cristiana» ${ }^{18}$.

Hay, pues, unas situaciones de los catecúmenos que pueden y deben ser reconducidas hacia la verdadera fe, pues presentan motivos no plenamente válidos, pero que pueden llegar a serlo, por ser susceptibles de una educación, fruto de la catequesis; por el contrario, otros motivos, resultan inaceptables, y la única respuesta coherente es la negativa. Pero incluso en el caso de sentir una cosa y manifestar unos falsos motivos que propiciaran su ingreso en la Iglesia, hace una clara llamada a la cordura evangélica evitando identificar la pertenencia externa a la Iglesia con la inclusión en el reino de los cielos. Todo ello conduce a ver en Agustín los derroteros por donde ha de discurrir una sincera conversión que pueda ser llamada con el nombre de tal, dejando de lado las falsas y aparentes conversiones. Él mismo tuvo personal experiencia de tal cambio interior.

\section{EL CONTENIDO DE LA CATEQUESIS}

Como es natural, Agustín no se preocupa únicamente de proporcionar consejos a Deogracias sobre las intenciones de los catecúmenos y las posibilidades pastorales que ellas ofrecen. Otro motivo de preocupación, básica para todo catequista, es la cuestión de los contenidos a transmitir, de manera que Agustín no constituye una excepción a la regla y suministra una serie de ideas importantes.

Con todo, es preciso advertir que tanto en De catechizandis rudibus como en otros tratados de corte catequético anteriores y posteriores a éste (De agone christiano, del año 396; De doctrina christiana, del mismo año; Enchiridion ad Laurentium, del 423) no trata de confeccionar un catecismo, en el sentido en que hoy entendemos el término, como una exposición breve, sistemática y completa de la fe cristiana. De ahí las lógicas diferencias de planteamiento y las consiguientes «deficiencias» en cuanto a ciertas omisiones o lagunas en sus

18. De catechizandis rudibus, 5,9. 
escritos catequéticos, justificadas plenamente en el sentido de que o bien responde a una visión no total de la fe, o bien hace referencia directa a las cuestiones debatidas y de más estricta actualidad en su momento, lo que obliga a remarcar ciertos acentos que resultan entonces particularmente urgentes. Pero es claro que tales omisiones o silencios no equivalen a negaciones.

De ahí que la primera observación que Agustín realiza sobre el contenido de la catequesis sea el de insistir en la historia de la salvación, es decir, ir haciendo una catequesis de la acción de Dios desplegada en la historia para ir aprendiendo de ella el modo de conducta de Dios para con los hombres y la respuesta que éstos han de darle por esa actuación. Desde el capítulo 18 hasta el 25 del De catechizandis rudibus, hace un desarrollo de este modelo de explicación histórica, siguiendo paso a paso los principales momentos de la relación de Dios con los hombres. Con mayor brevedad, propone a Deogracias otro modelo de explicación más breve (capítulo 26-27) en que se ciñe más sintéticamente a lo substancial de los hechos presentados, pero manteniendo siempre el principio de la panorámica de la historia de la salvación.

Se trata, pues de una explicación o catequesis fundamentalmente bíblica, pero no desprovista de ribetes teológicos, que suponen la lectura creyente realizada en sensibilidad o conexión con la Iglesia, a diferencia de la otra lectura bíblica suministrada por el pensamiento maniqueo, del que Agustín se ha ido distanciando desde el momento de su conversión. Pero tal lectura bíblica está reforzada por unas pinceladas de honda reflexión que el propio Agustín proporciona en cuanto al contenido de la fe, ya que recomienda no una avalancha de narraciones o datos bíblicos, como si estuviera adecuadamente presentada la fe por el hecho de acudir a la Biblia, sino que la matización va por otra vía:

«Tenemos una explicación completa si la catequesis comienza por aquello que está escrito 'Al principio creó Dios el cielo y la tierra' y continúa hasta los momentos presentes de la Iglesia. Mas no por eso debemos recitar de memoria, aunque lo hubiéramos aprendido palabra por palabra, ni explicar detalladamente con nuestro léxico, todo lo que se contiene en los Libros Sagrados (...); más bien hay que recoger todos los datos en compendio y de modo general, de forma que se elijan los hechos más admirables (quaedam miribiliora)..." ${ }^{19}$.

Por consiguiente, la primera labor del catequista al presentar la materia de la fe es la de una cuidadosa selección de los hechos más admirables, más importantes o nucleares, en torno a los cuales gravitan las claves de la historia de la salvación. Todo no tiene idéntica importancia y es preciso destacar algunos hechos que ocupan un lugar preponderante: creación, alianza, pascua, promesa, destierro, liberación..., constituyen —en nuestra terminología actual-

19. De catechizandis rudibus, 3,5. 
los hitos que Agustín señala como destacables. Pero junto a la selección, se impone al catequista una segunda y no menos importante tarea, la de la contemplación, pues resulta totalmente ineficaz una catequesis que se reduzca a un mero sucederse de hechos y narraciones en las que no se ahonda. Éstas son sus palabras:

«...de ahí que no se deben presentar estos hechos como superficialmente y retirarlos al instante de la consideración, sino deternerse un poco en desenredarlos y extenderlos, por así decir, y ofrecerlos a la admiración de los oyentes para su examen y consideración. De este modo aquellos datos, que queremos sean especialmente atendidos, sobresaldrán más ante la atenuación de éstos...» ${ }^{20}$.

La mera presentación de los datos más importantes de la fe es insuficiente si no se resaltan adecuadamente los momentos cruciales, y ésa es labor del catequista al transmitir el contenido de la fe. Preciosa recomendación que en nuestros días tiene plena vigencia por la enorme superficialidad con que vive el hombre audiovisual acostumbrado a disponer de un ingente volumen de información de fácil acceso, pero en la que ahonda y profundiza poco. Y la fe no es el barniz último que recubre a la persona, sino la actitud que brota del corazón, de lo íntimo: he aquí la necesidad de profundización.

A la hora de seleccionar un acontecimiento central que articula, explica y da sentido a los demás, Agustín no encuentra otro que la presencia de Cristo en medio de los hombres, como culminación del amor divino:

«Resulta que Cristo vino especialmente para que el hombre conociera cuán grande es el amor de Dios para con él...

...El mismo Señor Jesucristo, Dios encarnado, es la señal del amor de Dios para con nosotros y es el modelo de la humildad humana entre nosotros...» ${ }^{21}$.

Es claro que la idea de cristocentrismo de que habla la catequesis moderna como una reacción contra una excesiva proliferación de datos que no permitía distinguir lo fundamental de lo accesorio, ha sido adecuadamente percibida por Agustín y recomendada al catequista Deogracias. Por eso mismo insiste en la recomendación -enormemente actual- de leer el Antiguo Testamento desde el Nuevo, a la luz de Cristo:

«Según esto, en el Antiguo Testamento está la velación del Nuevo y la clave del Antiguo se halla en el Nuevo» ${ }^{22}$.

Con ello percibimos el lugar central que la Escritura ocupa en la mente de Agustín, como módulo central de la catequesis específicamente cristiana, que

20. De catechizandis rudibus, ibid.

21. Id., 4,8 .

22. Id., ibid. 
se nutre constante y habitualmente del alimento de la palabra de Dios. Ello no es obstáculo para abordar una serie de cuestiones que resultan especialmente necesarias en el momento en que Agustín escribe, precisamente por la atención a las carencias o dificultades sentidas o expresadas por los candidatos al catecumenado, o percibidas por el ojo clínico del catequista. Por eso recomienda que a los más torpes,

después de un breve recorrido por las demás cuestiones, se le han de inculcar las que son especialmente necesarias: la unidad católica, las tentaciones, la conversión cristiana motivada por el temor al juicio futuro»» ${ }^{23}$.

Como ya hemos indicado, tales cuestiones «especialmente necesarias» lo son para el momento y las circunstancias en que Agustín escribe, pero no han de entenderse en términos absolutos. De ahí que no se haga ni siquiera referencia implícita a la afirmación de $\mathrm{Hb}$ 11,6: «El que se acerca a Dios debe creer que existe y que recompensa a quienes lo buscan». Y también el hecho de que en algunos comentarios al De catechizandis rudibus se hayan señalado algunas carencias con relación al contenido de la fe que Agustín presenta, no tienen más trascendencia que el comprobar que no ha pretendido realizar una presentación absoluta de la fe cristiana ${ }^{24}$.

Pero en cambio, Agustín sí que ha pretendido manifestar expresamente al catequista Deogracias - y a todos los demás - que hay algo que tener en cuenta en la catequesis, y que afecta no tanto al contenido, sino a la esencia misma de la transmisión de la fe y, consecuentemente, ha de hacerse extensiva a la catequesis dirigida a hombres torpes así como a personas cultas. Se trata de que el catequista tome conciencia clara de que es mero transmisor de una creencia y una vida que le trasciende y que apuntan a su verdadera fuente, a Dios. Por lo cual no es ociosa la recomendación:

«habrán de explicarse muchas cosas, más a Dios en favor de él [el catecúmeno], que a él acerca de Dios» ${ }^{25}$.

Prima el sentido de la oración, de la súplica a Dios, que es en definitiva

23. De catechizandis rudibus, 13,18. Sobre la unidad de la Iglesia el propio Agustín se vio en la necesidad de escribir un tratado; acerca de las tentaciones, ya hemos tenido oportunidad de ver algunas de las que pueden asaltar al catecúmeno a la vista del deficiente ejemplo de los cristianos, y sobre la conversión movida por un motivo poco convincente, también hemos visto el pensamiento de Agustín (Id., 17,26).

24. Hace una presentación más sistemática de la fe en Enchiridion ad Laurentium, sobre el esquema de articular ésta en torno a la fe, esperanza y caridad, afirmando que el Símbolo y el $\mathrm{Pa}$ drenuestro contienen y expresan todo ello. Semejante contenido, articulado también en torno a las tres virtudes aparece en De agone christiano, así como en De doctrina christiana. No obstante, todos ellos responden a las necesidades de su época.

25. De catechizandis rudibus, 13,18. Algo semejante afirma en De doctrina christiana, 1,4, c. 30, n. 63 al decir: "Cuando un orador tenga que hablar al pueblo o a un grupo más reducido (...) ore para que Dios ponga en sus labios palabras propicias». 
quien habla al corazón del hombre y hace oír su voz, antes que el disponer de una teoría bien construida pero fría acerca de Dios. El lenguaje religioso más que hablar sobre Dios habla con Dios, y el catequista no se siente en modo alguno «propietario» de una doctrina, sino mero intermediario para que Dios y el hombre se pongan en contacto ${ }^{26}$.

Finalmente hemos de incluir en el presente apartado una breve, pero substanciosa recomendación que Agustín dirije a Deogracias a través de la cual pide el que la catequesis busque el asentimiento de los catecúmenos, pero en modo alguno el asentimiento obsequioso pero inconsciente, poco reflexivo o adocenado, sino muy al contrario, al asentimiento consciente, fruto del doble mutuo esfuerzo de explicación y aceptación, el asentimiento sincero, que responde al desarrollo de la fe y a la maduración en la misma fe; sus mismas palabras resultan suficientemente elocuentes:

«El pueblo ha de decir 'Amén' a lo que entiende plenamente» ${ }^{27}$.

De tal manera que ese «Amén» es la culminación de todo un proceso de aprendizaje, maduración y puesta en práctica de la vida cristiana, que ha sido suficientemente presentada y explicada como para que el catecúmeno pueda hacerla suya y expresarlo con tal fórmula consagrada: el «amén» de la catequesis, como el «amén» de la celebración litúrgica ${ }^{28}$, son la expresión consciente de madurez y de apropiación del contenido de la catequesis.

\section{El CATEQuista}

Si hemos tenido oportunidad de ver cómo Agustín perfila unas condiciones que han de marcar la imagen del catecúmeno que accede a la Iglesia, también vuelve sus ojos al catequista, precisamente porque él ha sido catequista y desde su conocimiento práctico y experiencial ha visto cómo se ha de actuar a la hora de proceder a la educación de la fe. Su De catechizandis rudibus, sin ser un tratado sistemático de formación de catequistas, contiene algunos elementos que vamos a destacar, dejando para otro apartado el relativo al modo

26. Evangelii nuntiandi, 60 expresa esta misma idea: «Ningún evangelizador es dueño absoluto de su acción evangelizadora, con un poder discrecional para cumplirla según los criterios y perspectivas individualistas..»; y Catechesi tradendae, 30 lo ratifica: «A ningún verdadero catequista le es lícito hacer por cuenta propia una selección en el depósito de la fe».

27. De catechizandis rudibus, 9,13 .

28. Con referencia al uso litúrgico del «Amén», Agustín dice: «Si, pues, vosotros sois el cuerpo y los miembros de Cristo, lo que está sobre la santa mesa es un símbolo de vosotros mismos, y lo que recibís es vuestro mismo emblema. Vosotros mismos lo refrendáis al responder: 'Amén'. Se os dice: 'He aquí el cuerpo de Cristo', y vosotros contestáis: 'Amén'; Así es. Sed, pues, miembros de Cristo para responder con verdad: ‘Amén'» (Sermón 272). «...Quita la palabra, únicamente hay pan y vino; añade la palabra, y se realiza el sacramento. A esto decís 'Amén'. Decir 'amén' equivale a subscribir algo. En latín 'Amén' se traduce como 'es verdadero'» (Sermón 6,3 [Denis]). 
de hacer o a la metolodogía que el catequista puede emplear. Ahora vamos a centrarnos en la persona misma del catequista, su papel eclesial, su talante.

Sin lugar a dudas es preciso destacar como la más importante afirmación que realiza en esta materia, la de considerar al catequista como un mero «ins trumento» en manos de Dios, en la más pura conexión con la teología paulina de los servidores del evangelio con arreglo a la cual «el que planta no significa nada ni el que riega tampoco; cuenta el que hace crecer, o sea, Dios (...). No sotros somos colaboradores de Dios» (ICor 3, 8-9). Y la primacía de la acción 
ra realizar la catequesis y va a traslucir su decaimiento; con ello mismo ya está señalando el remedio adecuado:

«...y si nos sucede así, nos disgustamos, nos debilitamos y nos abatimos en la misma tarea como si perdiéramos el tiempo trabajando en vano...

...Tal vez sucede que el abatimiento del interior proviene de algún escándalo y entonces se nos dice: 'Ven, háblale a éste; quiere hacerse cristiano'. Lo dicen quienes ignoran qué nos recome por nuestro oculto interior, y... cumplimos de mala gana lo que desean...

...y nos acercamos ya perturbados a la labor, para la que es indispensable una gran tranquilidad» ${ }^{32}$.

Si resulta importante la observación psicológica anterior, por lo mucho que influye el estado de ánimo en la labor a realizar, no menos aguda es la que ofrecemos a continuación, que está revestida, en nuestros días de una evidente actualidad, al haberse ido acentuando en los países europeos la diferencia más nítida entre catequesis de la comunidad y enseñanza religiosa escolar. Es la siguiente:

«No es necesario adoptar el tono autoritario del profesor» ${ }^{33}$.

Habría que hacer la salvedad de que la fórmula «no es necesario...» no sería adecuadamente entendida si se la interpretara en el sentido de «no es necesario, pero es conveniente». Se trata más bien de desaconsejar en términos absolutos que el catequista se dirija a los catequizandos como si sentara cátedra y no se tratara preferentemente de ir presentando y compartiendo la fe a la que procura iniciar. De ello se deduce que un cierto estilo magisterial no es el propio de la catequesis. A la fuerza tenemos que preguntarnos si tal afirmación la han hecho suya los muchos catequistas de nuestros días.

Abordando un problema específico de su momento, el del acceso al catecumenado de personas doctas en otros saberes ("gramáticos y oradores»), Agustín advierte a Deogracias para que no cometa el error de minusvalorarlos, mezclándolos con los hombres incultos (¡bien lo sabía él, que también ejerció la docencia!). Ahora bien, como una segunda advertencia que parece inicialmente dirigida a tales catecúmenos cultos, Agustín precisa que

«no se atrevan a comparar la destreza en la locuación con el corazón puro, cuando antes estaban acostumbrados a preferirla» ${ }^{34}$.

32. Id., 10,14. En este pasaje analiza Agustín las posibles razones del tedio y desánimo del catequista, señalando a continuación los remedios que estima más oportunos.

33. De catechizandis rudibus, 8,12 . Sobre la distinción entre catequesis de la comunidad y enseñanza religiosa escolar, puede consultarse COMISIÓN EPISCOPAL DE ENSEÑANZA Y CATEQUESIS, La enseñanza religiosa escolar (11 de junio 1979), en VARIOS, Documentos colectivos del Espiscopado Español sobre formación religiosa y educación, 1969-1980, Madrid, Edice 1981, 543-589, especialmente 564-566.

34. De catechizandis rudibus, 9,13 . 
Ahora bien, lo cierto es que aunque los destinatarios directos de tal recomendación sean los catecúmenos cultos, no se puede olvidar que indirectamente se está dirigiendo a los propios catequistas, pues a éstos advierte el peligro de no caer en la trampa de querer transformar su catequesis en una clase de retórica, pues entonces no sólo algunos de los oyentes estarán más preparados profesionalmente que los propios catequistas, sino que - lo que es mucho más grave- se estaría desvirtuando el mensaje cristiano: se estaría cumpliendo al pie de la letra lo formulado por Pablo: «Ya podría yo hablar las lenguas de los hombres y de los ángeles; si no tengo amor no soy más que un metal que resuena o unos platillos que aturden» (1Cor 13,1).

Finalmente, la última recomendación de Agustín a Deogracias en la que vamos a centrar nuestra atención está formulada en un contexto en que habla de los perversos, englobando en dicha categoría los que aparentemente están en la Iglesia aunque cordialmente no lo estén precisamente por su actitud y su conducta. Con referencia a ellos, Agustín dice:

«Sin duda no habrás de amar su injusticia, pero sí a ellos mismos a fin de que encuentren la justicia» ${ }^{35}$.

La distinción es clara y ningún catequista ha de tener temor en procurar ponerla en práctica, pues se trata de modificar las actitudes del corazón de las personas, transformando sus obras para que practiquen la justicia quienes la desconocían o la vulneraban; es preciso combatir al mal, pero no a quienes lo practican, aunque se perciba con claridad que no existe el mal más que en la medida en que es practicado por los perversos. Combatir la injusticia en sus mismas raíces es la mejor forma de erradicarla.

\section{Metodología}

Los aspectos de metodología catequética han sido tratado lo bastante en otra serie de comentarios al De catechizandis rudibus como para evitar ahora la repetición, de manera que únicamente vamos a centrarnos en unos pocos que han sido menos resaltados en ocasiones o comentarios anteriores.

En tal sentido, la primera nota que llama la atención al lector del tratado de Agustín es la respuesta que da al diácono Deogracias por la aridez que percibe en sus explicaciones y que le producen un hastío esterilizante én su actiyidad catequética. Agustín, conocedor de la materia, detecta una serie de remedios, el primero de los cuales es

«mis palabras no son tan frías como a mí me parecen» ${ }^{36}$,

35. De catechizandis rudibus, 27,55 .

36. Id., 2,4 . 
es decir, no se trata de buscar consuelo en una fácil y cómoda autoestimación que lleve al convencimiento de la perfección de la labor realizada; pero tampoco hay que ir al extremo contrario con la repulsa de todo lo dicho como si nunca se pudiera acertar. El convencimiento de la labor cuidadosamente realizada puede aportar la seguridad de que se dan unas ciertas garantía de éxito, sin tener que ser tan perfeccionistas como para aspirar al éxito total. Y lo subjetivo de la percepción de las propias palabras se tiene que equilibrar con lo objetivo de lo que otros percibieron en ellas.

Por ello, si en toda explicación influyen los elementos subjetivo y objetivo, tampoco aboga Agustín por la postura de la máxima comodidad invitando a creer que objetivamente siempre habrá habido elementos válidos, lo que salvaría toda explicación. Él mismo se vuelve exigente respecto a sus propias explicaciones y le pide a Deogracias que haga lo propio con relación a las que da a sus catecúmenos, en una verdadera revisión que conduzca a un mejoramiento:

«Muchas veces, al repasar nosotros mismos las cosas explicadas nos encontramos con errores y desconocemos la forma en que serían aceptados al pronunciarlos, y más nos preocupamos con dolor ante el hecho de que haya sido el error recibido con agrado...

A veces, inclusive, aun diciendo todas las cosas recta y acertadamente, desconcierta y extraña al oyente, bien alguna idea no captada, bien alguna idea lanzada contra la opinión corriente de un viejo error...

Pensando todo esto e invocando al Señor en nuestro corazón, tememos menos las imprevisibles consecuencias de nuestras palabras...» ${ }^{37}$.

Sin la obsesión de controlar las últimas e imprevisibles consecuencias de las palabras pronunciadas, que pueden suscitar reacciones diversas en el ánimo de los oyentes, se trata, ciertamente, de realizar un esfuerzo para conseguir la calidad de las explicaciones presentadas en la catequesis, aun a sabidendas de que resultará imposible predecir el eco que tales palabras van a suscitar en otros; la única solución posible es transmitir explicaciones de probada calidad, que eviten los riesgos de ser mal interpretadas.

Pero si es difícil prever los resultados, otra causa de desaliento, o por decirlo de otra manera, un resultado inmediato y claramente negativo es la falta de reacción de los oyentes:

«ese hastío se lo produce a quien habla el mismo oyente inmóvil, bien porque su sensibilidad no se inmuta, bien porque no indica con ningún gesto corporal que ha comprendido o que le agradan las cosas que se dicen»" ${ }^{38}$.

En esta situación ya no es tanto la calidad de la enseñanza el centro de las

37. De catechizandis rudibus, 11,16 .

38. Id., 10,14. 
preocupaciones de Agustín, sino la inexistente reacción de los catecúmenos que dejan desconcertado al catequista, sin saber si ha sido bien o mal recibida su explicación. Ciertamente en ocasiones es perferible la repulsa explícita que la ausencia de reacción, porque al menos la primera da a entender a las claras que ha sido captada, pero se está en desacuerdo con ella, mientras que la segunda no se significa en ningún sentido e incluso resulta difícil tratar de interpretarla.

Más adelante, Agustín propone el remedio a tal situación apuntando al catequista que lo que debe hacer es provocar el diálogo con el oyente de manera que por medio de él aparezca el nivel de aceptación, rechazo o entendimiento que el catequista ha suscitado ${ }^{39}$.

Otra de las cualidades que el catequista debe poseer es un dominio seguro de la materia que va a presentar, hasta el punto de que sea capaz de hacerla llegar al catecúmeno de la forma que éste mejor lo perciba, o según marquen las circunstancias. No es ocioso, pues el ejemplo que el mismo Agustín propone a Deogracias de una explicación más amplia de la fe (cap. 18-25), y, por contraste, un modelo más breve de instrucción (cap. 26,51 y 27): el catequista es capaz de detectar la situación y, seguro de lo que dice, saber responder a las necesidades que tiene presentes; en esta línea hay que situar el consejo de Agustín:

«cuando la rapidez ( = brevedad) se imponga necesariamente, observa qué fácilmente se puede explicar la totalidad de la materia» ${ }^{40}$,

de manera que presentando en cada caso lo fundamental de la fe, se puede acomodar a las disponibilidades de tiempo o a las necesidades del catequizando.

\section{LA ADAPTACIÓN}

Lo anteriormente señalado apunta a una de las cualidades básicas de que todo catequista debe estar dotado, porque no es mejor catequista quien repite con más fidelidad una doctrina preestablecida, sino quien es capaz de descubrir los medios o procedimientos para que la fe eclesial pueda ser entendida, captada y asumida por el sujeto a quien se dirige: es el principio de adaptación, que rige en gran medida toda la actuación del catequista y le obliga a ser permanente flexible, acomodándose al paso ágil o vacilante de quien va haciendo el camino con él. Ésta es la razón de que a continuación fijemos nuestra atención en una serie de advertencias o recomendaciones de índole pedagó-

39. Id., 13,18 .

40. Id., 26,51 . 
gica que tienen mucho que ver con la adaptación que el catequista está obligado a realizar.

Ya hemos visto cómo Agustín advierte que conviene enterarse indirecta y también directamente de las intenciones del catequizando, porque ello va a ser la clave de todo el esfuerzo de adaptación que el catequista realice. Pero enseguida introduce una modificación no despreciable, pues uno de los motivos de adaptación es precisamente la diferencia cultural de las personas, ya que ella va a marcar el estilo de hablar y actuar del catequista: es, por tanto, una exigencia fundamental a tener presente. Refiriéndose a los catecúmenos cultos, en primer lugar, aconseja conectar con sus intereses personales:

«...ciertamente no será inútil el preguntarle por qué motivos se vio impelido a querer ser cristiano...

...Convendrá el enterarse qué autor ha leído especialmente y a qué obras más intimamente se ha aficionado.

Después de que lo haya especificado, aprobémosle con alegría si conocemos esos libros, o, si, al menos, sabemos por las noticias de las Iglesias que han sido escritos por algún católico (...). Si por el contrario ha tropezado con los libros de algún hereje (...) francamente se le ha de decir la verdad» ${ }^{41}$.

Además del público culto, considera en segundo término a los hombres de escasa cultura, para los cuales la práctica de la adaptación ha de seguir forzosamente otros derroteros:

«mas con los más torpes hay que detenerse un poco más, ayudado de muchas palabras y comparaciones, para que no desprecien lo que sus sentidos no perciben» ${ }^{42}$.

Los párrafos aludidos son de por sí suficientemente expresivos de la forma de comportarse que el catequista ha de tener con aquellos a quienes destina su acción eclesial. Pero aún resulta más contundente en sus expresiones precaviendo al catequista de que huya de la alta especulación pues la catequesis no tiene esa finalidad; por lo cual,

«tenemos la obligación de descender, de la manera que sea, de las cimas de este pensamiento" ${ }^{43}$.

$\mathrm{Y}$ para reforzarlo, alude tres motivos en orden decreciente de importancia: $10^{\circ}$ Jesús se abajó hasta el aniquilamiento por los hombres; $2 .^{\circ}$ la madre está dispuesta a hacerse pequeña por sus hijos; $3 .^{\circ}$ la gallina cobija a sus pollos ante las aves de presa.

A lo largo de los capítulos 10 al 15, aparecen numerosas oportunidades de realizar una adaptación práctica a la situación de los catecúmenos, pero al

41. De catechizandis rudibus, 8,12 .

42. Id., 9,13 .

43. Id., 10,15 . 
392

L. RESINES

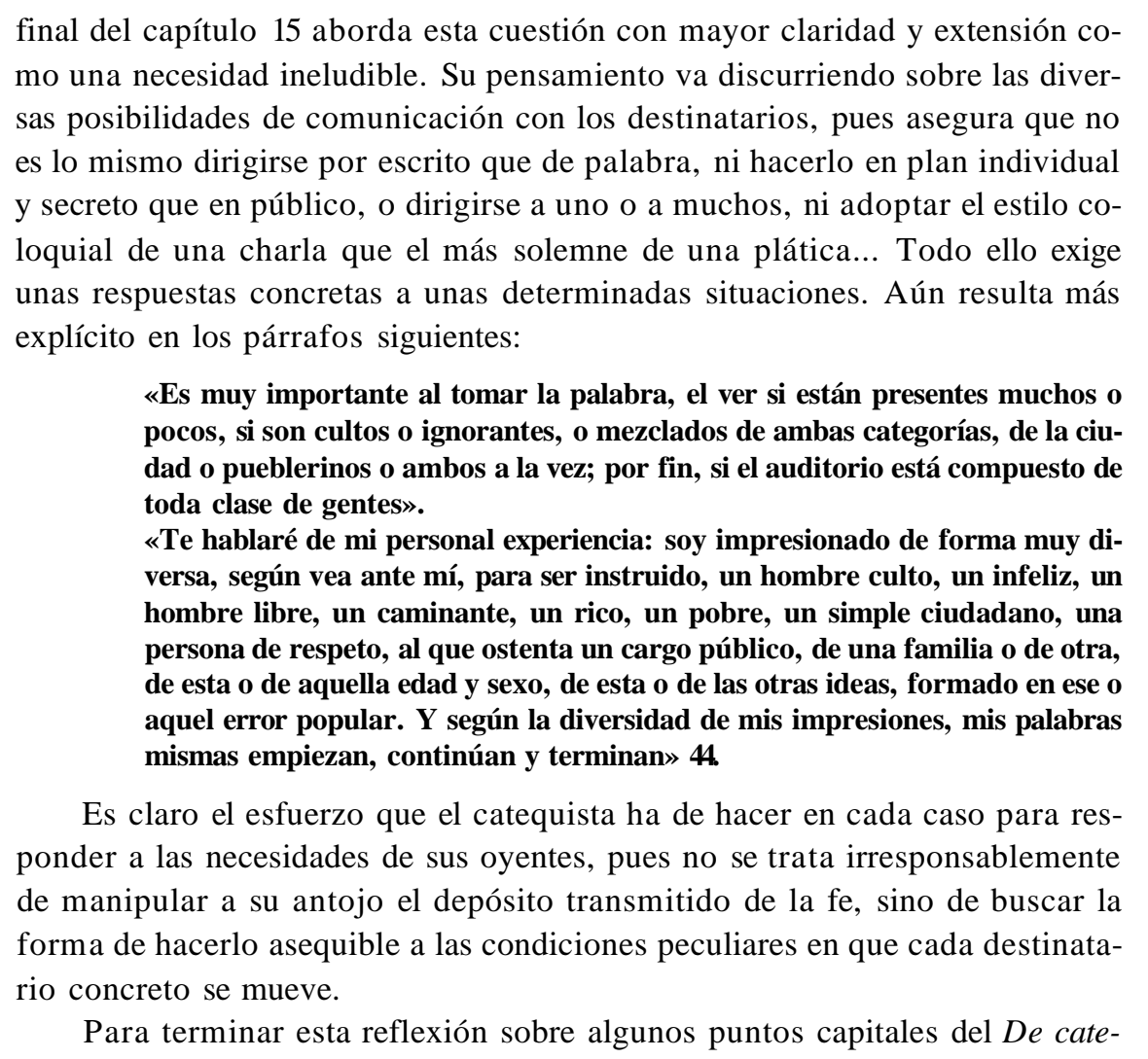

chiz nd s rud bus,

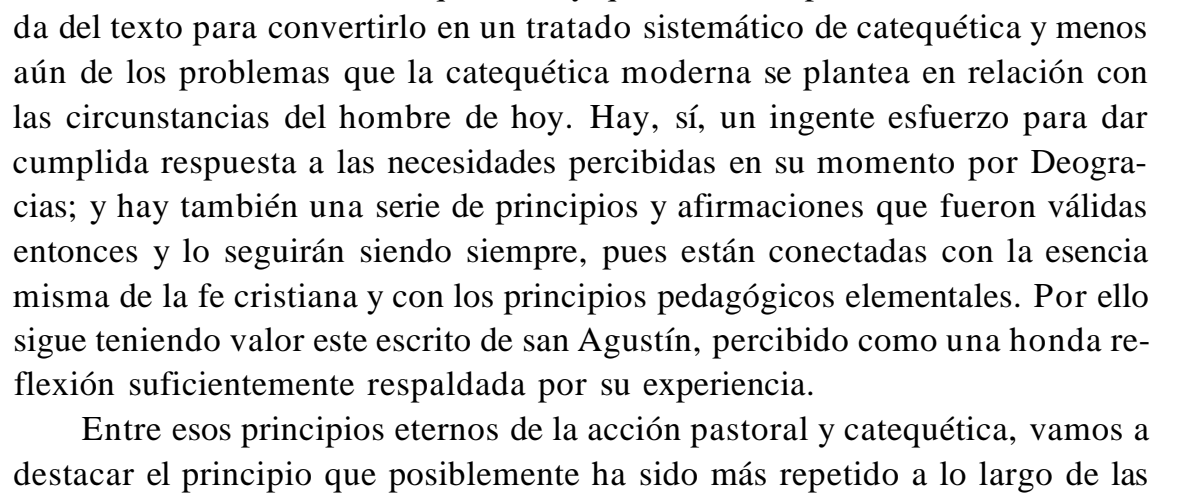

44. De ate $h$ zandis rud bus, 15,23. 
reflexiones catequéticas de todos los tiempos, y que resume como ninguno las preocupaciones y consejos de Agustín:

«Teniendo, pues, ante tus ojos este amor [de Dios] aquello que expliques hazlo de forma que tu oyente oyendo crea, creyendo espere y esperando ame» 45

LUIS RESINES

Estudio Teológico Agustiniano

Valladolid

45. Id. 